\title{
ObTenCIÓN DE DEHIDRODIISOEUGENOL POR DIMERIZACIÓN DE ISOEUGENOL CON CULTIVOS CELULARES DE Bouvardia ternifolia (TROMPETILLA)
}

\author{
Liliana Hernández-Vázquez, ${ }^{1 a}$ Ma. Teresa de Jesús Olivera-Flores, ${ }^{2}$ \\ Héctor Luna ${ }^{1}$ y Arturo Navarro-Ocaña ${ }^{3 b}$ \\ ${ }^{1}$ Departamento de Sistemas Biológicos, Universidad Autónoma Metropolitana-Xochimilco, Calzada del \\ Hueso \#1100, Col. Villa Quietud, Deleg. Coyoacán, C.P. 04960, Ciudad de México, México. ${ }^{2}$ Departamento \\ de Bioquímica, Laboratorio de Cultivos Vegetales, Facultad de Química, Universidad Nacional Autónoma \\ de México. Ciudad Universitaria, Deleg. Coyoacán, C.P. 04510, Ciudad de México, México. ${ }^{3}$ Departamento \\ de Alimentos y Biotecnología, Facultad de Química, Universidad Nacional Autónoma de México (UNAM), \\ Ciudad Universitaria, Deleg. Coyoacán, C.P. 04510, Ciudad de México, México. \\ E-mails: 1alhernandez@correo.xoc.uam.mx, ${ }^{3 b}$ arturono@unam.mx
}

\begin{abstract}
Resumen
Los cultivos celulares de Bouvardia ternifolia fueron usados como catalizadores en la reacción de acoplamiento oxidativo de isoeugenol. El compuesto dimérico dehidrodiisoeugenol se obtuvo con 77 \% de rendimiento cuando se usó el sobrenadante obtenido de un cultivo de células en suspensión, que poseía actividad de peroxidasa. La conversión procede en condiciones suaves de reacción y al adicionar el peróxido de hidrógeno disminuye el rendimiento en la obtención del dehidrodiisoeugenol.
\end{abstract}

Palabras Clave: acoplamiento oxidativo, Bouvardia ternifolia, cultivo celular, dehidrodiisoeugenol, isoeugenol.

\section{Dehidrodiisoeugenol by dimerization of isoeugenol with cell culture of Bouvardia ternifolia}

\begin{abstract}
Cell cultures of Bouvardia ternifolia were used as catalyst for the oxidative coupling of isoeugenol, to produce dehydrodiisoeugenol, a dimer, $77 \%$ isolated yield, when using the supernatat from the cell cultures suspension having peroxidase activity. The biotransformation proceeded under very mild conditions. It was observed that an increase in the amount of hydrogen peroxide decreases the yield.
\end{abstract}

Key Words: oxidative coupling, Bouvardia ternifolia, cell culture, dehidrodiisoeugenol, isoeugenol. 


\section{INTRODUCCIÓN}

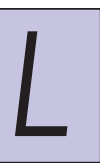
os $O$-metoxifenoles como el isoeugenol (2-metoxi4-(1-propenil) fenol), son constituyentes de aceites esenciales en una gran diversidad de plantas(Wenqiang et al., 2007). El isoeugenol es usado en perfumes, jabones, detergentes, aromatizantes, cosméticos, productos alimenticios (Findik et al., 2011) y material de partida para la síntesis de vainillina usando microorganismos(Hua et al., 2007) así como también para la preparación de salvinal (Wang et al., 2006) y otros derivados (Findik et al., 2011). El acoplamiento oxidativo del isoeugenol produce compuestos diméricos como el dehidrodiisoeugenol $(( \pm)$ licarina A), y diisoeugenol (Figura 1) (Nascimento et al., 2000). El dehidrodiisoeugenol es el compuesto mayoritario y el más activo de los compuestos fenólicos presentes en Myristica fragrans (Juhász et al., 2000), ya que posee una potente actividad antiinflamatoria y antibacterial (Murakami et al., 2005), actividad esquistosomicida y tripanocida (Pereira et al., 2011).

Los cultivos celulares obtenidos de plantas, poseen un gran potencial bioquímico para la obtención de metabolitos secundarios. Así como para la transformación de sustratos exógenos en productos de interés farmacéutico. En la naturaleza se encuentran compuestos estructuralmente complicados, poco abundantes y de obtención costosa, pero gracias a las biotransformaciones en las que los cultivos celulares actúan como biocatalizadores, se ha encontrado una alternativa para que a partir de productos naturales simples, pero abundantes y de obtención barata, se extraigan los compuestos estructuralmente complicados. Las reacciones catalizadas por cultivos celulares incluyen hidroxilaciones, oxidaciones, reducciones, hidrogenaciones e hidrólisis (Giri et al., 2001; Suga \& Hirata, 1990; Ishihara et al., 2003).

El desarrollo de biocatalizadores, para la oxidación de compuestos orgánicos, en específico para los fenoles, es una importante y versátil área de investigación.

Recientemente, informamos que los cultivos celulares obtenidos a partir de Medicago sativa (alfalfa), Bouvardia ternifolia (trompetilla), Prunus serotina (capulín), Coriandrum sativum (cilantro), Phaseolus vulgaris (frijol), Mammillaria hutzilopochtli, Psacalium peltratum, Cucumis melo (melón) y Dacus carota (zanahoria) son capaces de trasformar a los $O$-metoxifenoles como el eugenol e isoeugenol en compuestos diméricos vía la reacción de acoplamiento oxidativo, catalizada por peroxidasas, como el dehidrodieugenol (HernándezVázquez et al.,2011). El mecanismo de reacción que se propone (Figura 2) para la dimerización está basado en los reportes de Moussouni et al., 2011 y Anita et al., 2014 los cuales indican qué peroxidasas vegetales transforman fenoles sustituidos con un grupo metoxilo en la posición orto al correspondiente $O$-radical, que al estabilizarse por resonancia produce un $C$-radical; este último es el que conduce a la dimerización como lo indica lo reportado por Bartolomeazzi et al., 2010 produciendo un dímero. Esta biotransformación representa una alternativa más limpia y verde a los métodos químicos tradicionales en los que las reacciones de acoplamiento oxidativo se efectúan usando catalizadores como $\mathrm{FeCl}_{3}, \mathrm{~K}_{3}(\mathrm{FeCN})_{6}$ y $\mathrm{Cu}(\mathrm{OH}) \mathrm{Cl}$ (Farías-Días,1988). Sánchez \& Fernández, 1983, informaron<smiles>C/C=C/c1ccc(O)c(OC)c1</smiles>

Isoeugenol (1)<smiles>C/C=C/c1cc(OC)c2c(c1)C(C)C(c1ccc(O)c(OC)c1)O2</smiles>

Dehidrodiisoeugenol (2)<smiles>CCC1c2cc(OC)c(O)cc2[C@H](c2ccc(O)c(OC)c2)C1C</smiles>

Diisoeugenol (3)<smiles>C=CCc1ccc(O)c(OC)c1</smiles>

Eugenol (4)<smiles>C=CCc1cc(CC=C)cc(-c2c(O)c(OC)cc(OC)c2O)c1</smiles>

Dehidrodieugenol (5)

Figura 1. Estructuras de isoeugenol, eugenol y sus dímeros. 


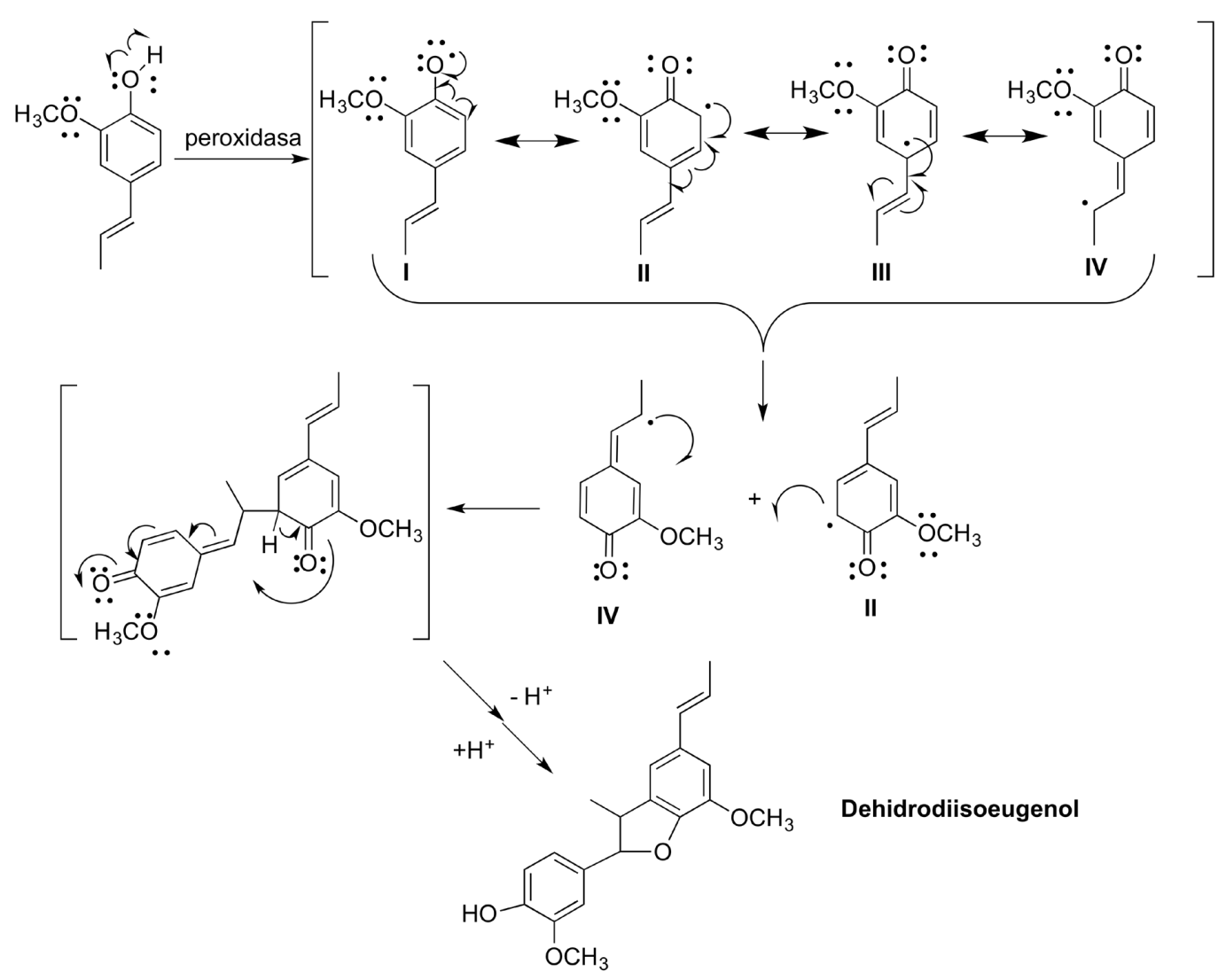

Figura 2. Mecanismo propuesto para la dimerización del isoeugenol a dehidrodiisoeugenol.

que diferentes explantes pueden ser usados para la obtención del callo homogéneo de $B$. ternifolia y también que las propiedades bioquímicas de los callos pueden ser modificadas cambiando la fuente de nitrógeno.

En este trabajo reportamos el uso de cultivos celulares de $B$. ternifolia para la síntesis de dehidrodiisoeugenol partiendo del isoeugeol (Figura 3).

\section{Materiales y métodos}

Los reactivos se adquirieron en Sigma-Aldrich y se usaron sin purificar. Los espectros de $\mathrm{RMN}{ }^{1} \mathrm{H}$, se obtuvieron en un equipo Varian 400 en $\mathrm{CDCl}_{3}$ y se utilizó tetrametilsilano (TMS) como referencia interna. La cromatografía en capa fina $(\mathrm{CCF})$ fue utilizada de manera preliminar para determinar la presencia de los productos de las biotransformaciones. Se utilizaron placas de sílica gel en aluminio, Sílica gel Alugram ${ }^{\circledR}$ SIL G/ $\mathrm{UV}_{254}, 0.2 \mathrm{~mm}$, Macherey-Nagel y una mezcla de hexanoacetato de etilo (4:6) como eluyente. Para la cuantificación del dehidrodiisoeugenol obtenido de la biotransformación, se utilizó cromatografía de líquidos de alta resolución (HPLC) y un equipo Waters-1525 HPLC equipado con detector UV Waters 2487. La columna empleada fue una Symmetry ${ }^{\circledR}$ C-18 a $280 \mathrm{~nm}$, con flujo de $1 \mathrm{~mL} / \mathrm{min}$ de una mezcla de ácido trifluoroacético (0.1\%)-acetonitrilo (Ramachandra \& Ravishankar, 1999). Se elaboraron curvas patrón en donde se usó isoeugenol en un rango de concentraciones de 0 a $0.8 \mathrm{mg} / \mathrm{mL}$ y dehidrodiisoeugenol de 0 a $8 \mathrm{mg} / \mathrm{mL}$, para determinar los rendimientos de reacción y los porcentajes de recuperación del sustrato.

\section{Obtención del callo de Bouvardia ternifolia a partir de hojas e inflorescencias}

Los callos de B. ternifolia fueron establecidos partiendo de hojas jóvenes e inflorescencias de plantas de trompetilla colectadas en Ciudad Universitaria (UNAM).

\section{Método de desinfección de hojas e inflorescencias}

Las hojas jóvenes e inflorescencias fueron lavadas con agua y jabón. Éstas se pusieron en una caja Petri con etanol al $70 \%$ por 1 min y se lavaron tres veces con agua esterilizada. Posteriormente, se colocaron en agitación constante con una disolución al $20 \%$ de hipoclorito de sodio comercial $(\mathrm{NaClO}$ con $6 \%$ de ingrediente activo), $0.1 \%$ de tween y $10 \mu \mathrm{L}$ de Mycrodyn ${ }^{\circledR}$, por 20 minutos, se lavaron tres veces con agua esterilizada. Después a las hojas e inflorescencias se les adicionaron $250 \mathrm{~mL}$ de Promil ${ }^{\circledR}(2 \mathrm{~g} / 250 \mathrm{~mL})$ y esta mezcla se agitó por $30 \mathrm{~min}$, 


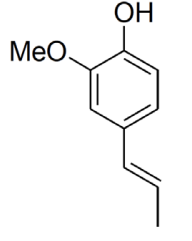

Isoeugenol (1)
Callo disgregado

en buffer de fosfatos

0

Sobrenadante de callo o células en suspensión

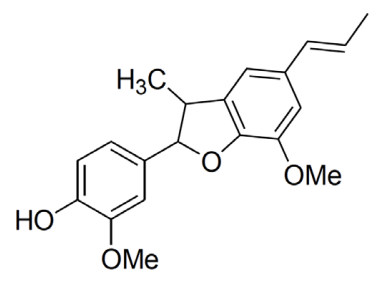

Dehidrodiisoeugenol (2)

Figura 3. Reacción de obtención de Dehidrodiisoeugenol a partir de isoeugenol.

se enjuagaron tres veces más con agua esterilizada. Al cabo de este tiempo se adicionaron $250 \mathrm{~mL}$ of Agrimicin ${ }^{\circledR} 1 \mathrm{~g} / 250 \mathrm{~mL}$ y se agitaron por $20 \mathrm{~min}$, posteriormente se enjuagaron cuatro veces con agua esterilizada.

\section{Siembra de explantes e inducción de callo}

Las hojas y flores (explantes) se pusieron en una disolución 1:1 de ácido ascórbico y cítrico $(100 \mathrm{mg} / \mathrm{L})$. Las hojas se cortaron en segmentos de $1 \mathrm{~cm}^{2}$ y las flores se cortaron en cuatro segmentos colocándolas en el medio de cultivo Murashige and Skoog (MS) (Sánchez \& Fernández, 1983) suplementado con sacarosa (3\%), ácido 2,4-diclorofenoxiacético (2,4-D, $1 \mathrm{mg} / \mathrm{L}$ ), ácido ascórbico $(50 \mathrm{mg} / \mathrm{L})$ - ácido cítrico $(50 \mathrm{mg} / \mathrm{L})$, quinetina $(0.05 \mathrm{mg} / \mathrm{L})$, cefotaxime $(250 \mathrm{mg} / \mathrm{L})$ y gelzan ${ }^{\mathrm{TM}} \mathrm{CM}$ como agente gelante $(2.5 \mathrm{~g} / \mathrm{L})$, se ajustó el pH 5.7. Las condiciones de incubación fueron $25 \pm 2{ }^{\circ} \mathrm{C}$, con 16 horas de luz y 8 de obscuridad. El primer subcultivo se realizó después de tres semanas, el callo se conservó en medio MS sólido y se subcultivó cada tres semanas (21 días, Figura 4).

\section{Obtención de cultivos celulares en suspensión}

El medio que se usó fue el mismo pero sin gelzan ${ }^{\mathrm{TM}} \mathrm{CM}$, el cultivo se estableció por inoculación de $10 \mathrm{~g}$ de callo de hojas en un matraz Erlenmeyer con $250 \mathrm{~mL}$ del medio MS antes descrito, las condiciones de incubación son las mismas que se describieron anteriormente para la generación de callos, pero bajo agitación constante $(150 \mathrm{rpm})$. Las células fueron subcultivadas por intervalos de 14 días. Al cabo de este tiempo este cultivo se filtró al vacío y se tomaron $20 \mathrm{~g}$ de estas células con las que se realizó la biotransformación.

Adicionalmente, se obtuvieron cultivos de células en suspensión de B. ternifolia de hoja en estrés nutritivo, para lo cual se utilizó el medio antes descrito, pero se redujo el porcentaje de nitratos del medio a un $50 \%$ y $25 \%$.

\section{Biotransformación con callo disgregado en una solución amortiguadora de fosfatos}

Se pesaron $20 \mathrm{~g}$ de callo de hoja y otro de inflorescencias y se adicionaron a un matraz Erlenmeyer que contenía $100 \mathrm{~mL}$

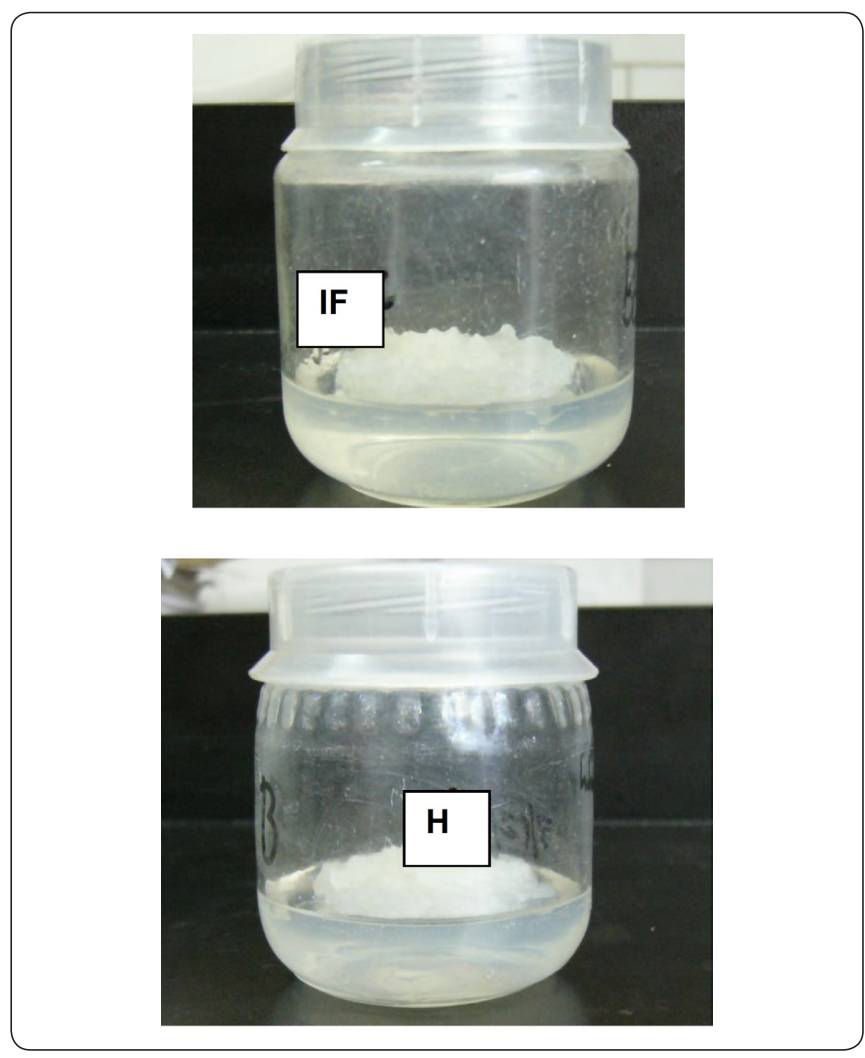

Figura 4. Callo de inflorescencias (IF) y hojas de B. ternifolia (H).

de solución amortiguadora de fosfatos $0.1 \mathrm{M} \mathrm{pH}$ 6, la mezcla se agitó a $150 \mathrm{rpm}$ en un agitador rotatorio. Posteriormente, a cada matraz se agregaron $25 \mathrm{mg}\left(1.52 \times 10^{-4}\right.$ moles $) \mathrm{de}$ isoeugenol que previamente se disolvió en $1 \mathrm{~mL}$ de acetona, se adicionó o no agua oxigenada ( $34.5 \mu \mathrm{L}, 3.04 \times 10^{-4}$ moles $)$ según el experimento. En todos los casos la reacción se realizó por triplicado, se usó un control que contuvo sólo los callos disgregados en el amortiguador de fosfatos y otro al que se adicionó todo excepto el sustrato. Las mezclas de reacción se colocaron en agitación a1 80 rpm durante 48 horas, al término de este tiempo, se filtró la suspensión de reacción para separar 
el sólido y el líquido y al filtrado se le hicieron dos extracciones con acetato de etilo (AcOEt, $50 \mathrm{~mL}$ x 2), se deshidrataron con sulfato de sodio anhidro $\left(\mathrm{Na}_{2} \mathrm{SO}_{4}\right)$ y se evaporaron a sequedad. Una muestra de la mezcla de reacción se analizó por HPLC bajo las condiciones que se describieron en el procedimiento general, ver resultados en la Tabla I. Las mezclas de reacción de las tres repeticiones se juntaron y se purificaron por cromatografía en columna.

El mismo procedimiento se realizó (Tabla II) para el callo obtenido en condiciones de estrés nutritivo.

\begin{tabular}{|c|c|c|c|}
\hline Muestra & Descripción & $\begin{array}{c}\text { Rendimiento } \\
(\%)\end{array}$ & $\begin{array}{c}\text { Recuperación } \\
\text { de isoeugenol } \\
(\%)\end{array}$ \\
\hline Control & *Callo & 2.0 & 0.0 \\
\hline Control & $*$ Callo, $\mathrm{H}_{2} \mathrm{O}_{2}$ & 3.0 & 1.0 \\
\hline Biotrans & $*$ Callo, isoeugenol & 45 & 24 \\
\hline Biotrans & $\begin{array}{l}* \text { Callo, isoeugenol } \\
\mathrm{y} \mathrm{H}_{2} \mathrm{O}_{2}\end{array}$ & 13.0 & 4.0 \\
\hline Control & **Sobrenadante & 0.0 & 0.0 \\
\hline Control & $\begin{array}{l}* * \text { Sobrenadante, } \\
\mathrm{H}_{2} \mathrm{O}_{2}\end{array}$ & 1.0 & 1.0 \\
\hline Biotrans & $\begin{array}{l}* * \text { Sobrenadante, } \\
\text { isoeugenol }\end{array}$ & 44.0 & 21.0 \\
\hline Biotrans & $\begin{array}{l}* * \text { Sobrenadante, } \\
\text { isoeugenol, } \mathrm{H}_{2} \mathrm{O}_{2}\end{array}$ & 44.0 & 2.0 \\
\hline
\end{tabular}

Tabla I. Resultados de las reacciones de obtención de dehidrodiisoeugenol a partir de isoeugenol con callo disgregado en solución amortiguadora de fosfatos y sobrenadante.

Biotransformación con el sobrenadante obtenido después de homogeneizar y centrifugar

Se pesaron $20 \mathrm{~g}$ de callo de hojas y $20 \mathrm{~g}$ de las células del cultivo en suspensión que se obtuvieron por filtración al vacío según se describió anteriormente. Estos callos o células se adicionaron a un matraz Erlenmeyer que contenía $100 \mathrm{~mL}$ de solución amortiguadora de fosfatos $0.1 \mathrm{M} \mathrm{pH} \mathrm{6,y} \mathrm{se} \mathrm{homogeneizaron}$ con ayuda de un homogeneizador Ultra-turrax IKA T10, se centrifugó a $1500 \mathrm{rpm}$ por $2 \mathrm{~min}$. Se recuperó el sobrenadante y éste se utilizó para la biotransformación de isoeugenol, para lo cual se adicionaron $25 \mathrm{mg}$ de isoeugenol previamente disuelto en $1 \mathrm{~mL}$ de acetona y $\mathrm{H}_{2} \mathrm{O}_{2}(34.5 \mu \mathrm{L}, 3.04$ X 10-4 moles) según sea el caso, la reacción se realizó por triplicado y dos controles: uno de ellos con sólo el sobrenadante y al otro se le adicionó todo excepto el sustrato. Las mezclas de reacción se pusieron en agitación continua a $180 \mathrm{rpm}$ durante 48 horas, al término de este tiempo, se filtraron, para separar sólidos y al filtrado se le realizó una extracción con AcOEt $(50 \mathrm{~mL}$ x 2), se secaron con $\mathrm{Na}_{2} \mathrm{SO}_{4}$ y se evaporaron a sequedad, Figura 3. Una muestra de

\begin{tabular}{|l|l|c|c|}
\hline Muestra & \multicolumn{1}{|c|}{ Descripción } & $\begin{array}{c}\text { Rendimiento } \\
\mathbf{( \% )}\end{array}$ & $\begin{array}{c}\text { Recuperación } \\
\text { de isoeugenol } \\
(\%)\end{array}$ \\
\hline Control & $*$ Callo N 100\% & 0.0 & 0.0 \\
\hline Biotrans & $\begin{array}{l}* \text { Callo N 100\%, } \\
\text { isoeugenol }\end{array}$ & 13.0 & 5 \\
\hline Control & $* *$ Callo N 50\% & 1.0 & 0 \\
\hline Biotrans & $\begin{array}{l}* * \text { Callo N 50\% } \\
\text { isoeugenol }\end{array}$ & 14.5 & 3 \\
\hline Control & $* * *$ Callo N 25\% & 1.0 & 0 \\
\hline Biotrans & $\begin{array}{l}* * * \text { Callo N 25\% } \\
\text { isoeugenol }\end{array}$ & 14.5 & 5 \\
\hline$*$ Callo de hojas disgregado en solución amortiguadora de fosfatos $\mathrm{y}_{2} \mathrm{O}_{2}$ \\
con 100, 50 y 25\% de nitratos.
\end{tabular}

Tabla II. Resultados de las reacciones de obtención de dehidrodiisoeugenol a partir de isoeugenol con callo disgregado generado en condiciones de estrés nutritivo.

la mezcla de reacción se analizó por HPLC bajo las condiciones que se describieron en el procedimiento general, ver resultados en la Tabla I y III.

El mismo método se efectuó para los callos y células en suspensión que crecieron en condiciones de estrés nutritivo (con $50 \%$ y $25 \%$ de nitratos).

\section{Purificación del dehidrodiisoeugenol producido en la biotransformación}

La mezcla de reacción se purificó por cromatografía en columna usando como soporte sílica gel y como eluyente una mezcla de diclorometano-hexano 1:1, se tomaron fracciones de $25 \mathrm{~mL}$, siguiendo la purificación por CCF reuniendo las primeras fracciones que contienen el isoeugenol recuperado y las fracciones posteriores en las que se eluyó al producto de la biotransformación del dehidrodiisoeugenol (40\% de rendimiento), se evaporaron a sequedad y el producto fue identificado por $\mathrm{RMN}^{1} \mathrm{H}$. ${ }^{1} \mathrm{H}$ RMN $\left(\mathrm{CDCl}_{3} / \mathrm{TMS}\right): \delta 1.37$ (d, $3 \mathrm{H}, \mathrm{J}=6.8 \mathrm{~Hz}), 1.86$ (dd, $3 \mathrm{H}, \mathrm{J}=6.8,1.6 \mathrm{~Hz}, 3.40-3.50$ (m, 1H), 3.84 (s, 3H), 3.88 (s, 3H), 5.09 (d, 1H, J = 9.6 Hz), 5.80 (s, 1H), $6.11(\mathrm{dq}, 1 \mathrm{H}, \mathrm{J}=15.6,110,6.4 \mathrm{~Hz}), 6.36(\mathrm{dd}, 1 \mathrm{H}, \mathrm{J}$ $=15.6,1.2 \mathrm{~Hz}), 6.76(\mathrm{~s}, 1 \mathrm{H}), 6.78(\mathrm{~s}, 1 \mathrm{H}), 111,6.86-6.91(\mathrm{~m}$, 2H), 6.96 (s, 1H); (Ramachandra \& Ravishankar, 1999)CRMN $\left(\mathrm{CDCl}_{3} / \mathrm{TMS}\right): \delta$ 17.4, 18.4, 45.5, 55.7, 55.8, 93.5, 108.6, $108.8,113,113.8,119.6,123.2,130.5,131.6$. Los datos son consistentes con los reportados en la literatura (Bartolomeazzi et al., 2010).

\section{RESULTADOS Y DISCUSIÓN}

Obtención de cultivos de Bouvardia ternifolia de hojas e inflorescencias

Los callos que se obtuvieron a partir de las hojas e inflorescencias presentaron una coloración crema y aspecto espumoso, no 


\begin{tabular}{|c|c|c|c|}
\hline Muestra & Descripción & $\begin{array}{c}\text { Rendimiento } \\
(\%)\end{array}$ & $\begin{array}{c}\text { Recuperación } \\
\text { de isoeugenol } \\
(\%)\end{array}$ \\
\hline Control & $\begin{array}{l}\text { *Sobrenadante N } \\
100 \%\end{array}$ & 4 & 1.0 \\
\hline Control & $\begin{array}{l}\text { *Sobrenadante } \mathrm{N} \\
100 \% \mathrm{y} \mathrm{H}_{2} \mathrm{O}_{2}\end{array}$ & 2 & 0.0 \\
\hline Biotrans & $\begin{array}{l}* \text { Sobrenadante } \\
\mathrm{N} 100 \%, \mathrm{H}_{2} \mathrm{O}_{2} \mathrm{e} \\
\text { isoeugenol }\end{array}$ & 0 & 1.0 \\
\hline Biotrans & $\begin{array}{l}* \text { Sobrenad ante } \\
\text { N100\% e isoeuge- } \\
\text { nol }\end{array}$ & 73 & 9.0 \\
\hline Control & $\begin{array}{l}\text { *Sobrenadante } N \\
25 \%\end{array}$ & 8.0 & 1.0 \\
\hline Control & $\begin{array}{l}* \text { Sobrenadante } \mathrm{N} \\
25 \%, \mathrm{H}_{2} \mathrm{O}_{2}\end{array}$ & 3.0 & 0.0 \\
\hline Biotrans & $\begin{array}{l}* \text { Sobrenadante } N \\
25 \% \text {, isoeugenol }\end{array}$ & 77 & 11 \\
\hline Biotrans & $\begin{array}{l}* \text { Sobrenadante } \\
\mathrm{N} 25 \%, \mathrm{H}_{2} \mathrm{O}_{2} \\
\text { isoeugenol }\end{array}$ & 46 & 3.0 \\
\hline
\end{tabular}

Tabla III. Resultados de las reacciones de obtención de dehidrodiisoeugenol a partir de isoeugenol con el sobrenadante de las células en suspensión generadas bajo condiciones de estrés nutritivo.

son susceptibles a la oxidación, son disgregables y aumentan rápidamente su masa en un periodo corto de crecimiento.

Los cultivos en suspensión de B. ternifolia, son de color crema y no presentan oxidación. Se realizó la cinética de crecimiento del cultivo de células en suspensión en peso seco y fresco por 14 días, debido a que se observó un crecimiento acelerado con la formación de agregados que dificultaban la toma de la muestra. En el periodo evaluado se observa que el crecimiento se presenta con una tendencia ascendente y con dos fases: la fase "lag" y la fase de crecimiento exponencial o lineal sin observarse la fase estacionaria. Los resultados obtenidos permiten concluir que los cultivos duplican su peso a los ocho días y lo cuatriplican a los 14 días. Esta etapa de crecimiento fue la seleccionada para efectuar las biotransformaciones.

Biotransformación de isoeugenol con callo disgregado en solución amortiguadora de fosfatos de inflorescencia y hoja De manera preliminar y para determinar si existe diferencia entre el uso de la hoja y la inflorescencia en la biotransformación de isoeugenol se realizaron las reacciones sin adición de peróxido de hidrógeno utilizando callos disgregados en solución amortiguadora de fosfatos de los dos explantes antes mencionados, las mezclas de reacción de las biotransformaciones fueron aplicadas en una cromatoplaca poniendo isoeugenol y dehidrodiisoeugenol como referencia, observando que en las placas de cromatografía no hubo consumo total de la materia prima, pero sí presencia de productos más polares que el isoeugenol, uno de ellos mayoritario con el mismo $R_{\mathrm{f}}$ el dehidrodiisoeugenol. Los resultados obtenidos indican que no existen diferencias observables entre el uso de los callos de las hojas o el de los callos de las inflorescencias, por lo que se decidió continuar con los cultivos celulares provenientes de las hojas para las demás biotransformaciones, Figura 4.

Biotransformación de isoeugenol con callo disgregado en solución amortiguadora de fosfatos y del sobrenadante

En la Tabla I se describen los resultados obtenidos de la biotransformación de isoeugenol con callos de hojas disgregados en solución amortiguadora de fosfatos y con el sobrenadante, con y sin adición de peróxido de hidrógeno. Se evaluó la influencia del $\mathrm{H}_{2} \mathrm{O}_{2}$, en la reacción, ya que los reportes indican que la adición de éste puede favorecer la formación de los productos de dimerización, por ser el sustrato de las enzimas peroxidasas. Sin embargo, también es sabido que un exceso del mismo puede disminuir los rendimientos (Figura 2).

Los datos presentados en la Tabla I, indican que se obtienen rendimientos moderados similares para las biotransformaciones con el callo disgregado y los sobrenadantes (45 y $44 \%$, respectivamente). Pero, para aquellos casos en los que se les adicionó peróxido de hidrógeno a la reacción, la biotransformación con el callo disgregado mostró una caída significativa en el rendimiento (13\%); mientras que con el sobrenadante no hubo tal efecto (44\%). La influencia del peróxido de hidrógeno en esta serie de reacciones no es clara. Rendimientos similares se obtienen cuando se usa la lacasa cruda y purificada de Rhus vercifera (41\%) (Shiba et al., 2000), pero menores a los resultados obtenidos por Nascimento et al., 2000 con peroxidasa pura de rábano $(90 \%)$. Cabe mencionar que la comparación se basa sólo en los rendimientos correpondientes, en el entendido que se trata de enzimas y condiciones de reacción diferentes, debido al interés preparativo de estos compuestos.

Por lo anterior, se puede proponer el mecanismo mostrado en la Figura 2, de acuerdo a lo propuesto por Anita et al., 2014 para guaiacol y por Moussouni et al., 2011, para el isoeugenol, en lo que respecta a sistemas $O$-metoxifenoles éste sería el radical formado por la peroxidasa y posteriormente el radical se dimeriza de acuerdo al mecanismo propuesto por Bartolomeazzi et al., 2010 en la reacción de formación de dehidrodiisoeugenol y dehidrodieugenol con DPPH de isoeugenol y eugenol, respectivamente.

Con respecto a la recuperación del isoeugenol, éste disminuye cuando se usan callos disgregados y también cuando se utiliza 
el sobrenadante en presencia de peróxido de hidrógeno. Esto puede ser debido a que el isoeugenol puede sufrir otras reacciones de acoplamiento oxidativo y formar trímeros, tetrámeros e inclusive polímeros.

Cabe resaltar que los cultivos celulares parecen formar pequeñas cantidades de isoeugenol en las condiciones evaluadas entre 0 y $1 \%$ y de dehidrodiisoeugenol entre $0-3 \%$, sin embargo, estos resultados pueden también ser debidos al error asociado al método de análisis.

La Tabla II presenta los resultados obtenidos con callo disgregado en solución amortiguadora de fosfato con $\mathrm{H}_{2} \mathrm{O}_{2}$ obtenidos en un medio donde se disminuyó la cantidad de nitratos a 50 y $25 \%$ (estrés nutritivo), puede observarse que los rendimientos en la obtención de dehidrodiisoeugenol aumentan cuando se disminuye la cantidad de nitrato es decir bajo condiciones de estrés, sin embargo, el incremento no es significativo. Como los resultados son iguales cuando se tiene un $50 \%$ y un $25 \%$ de nitratos en el medio, se decidió seguir el estudio empleando sólo los callos con $25 \%$ de nitratos.

Por último, presentamos una serie de experimentos que se realizaron con células en suspensión de B. ternifolia. Se eligió el uso de células en suspensión, en lugar de callo, con base en resultados previos, donde el uso de células en suspensión incrementa el rendimiento en la obtención de dehidrodieugenol a partir de eugenol con cultivos celulares de B. ternifolia ( Hernández-Vázquez et al., 2011).

Los resultados de estos experimentos se presentan en la Tabla III, como puede observarse el rendimiento se incrementa de manera importante a 73 y $77 \%$ cuando se usa el sobrenadante obtenido con $100 \%$ y $25 \%$ de nitratos respectivamente. Esto es indicativo de que las células en suspensión son mejores fuentes del biocatalizador que los callos, además que el estrés nutritivo genera un incremento en el rendimiento del dehidrodiisoeugenol. Nuevamente cuando se usa el sobrenadante, adicionando $\mathrm{H}_{2} \mathrm{O}_{2}$, el rendimiento disminuye a 0 y $46 \%$ para las células en suspensión obtenidas con $100 \%$ y $25 \%$ de nitratos respectivamente.

Los datos descritos indican que el sobrenadante obtenido a partir de células en suspensión, es un biocatalizador eficiente para la transformación de isoeugenol, aunque los rendimientos son menores a los informados por Nascimento et al, 2000 con peroxidasa de rábano pura $(90 \%)$.

Cabe resaltar, que en estas series de reacciones se utilizaron crudos enzimáticos, y las condiciones de reacción no fueron optimizadas para lograr el rendimiento máximo. Se determinó que la adición de $\mathrm{H}_{2} \mathrm{O}_{2}$ tuvo un efecto negativo en el rendimiento en la obtención de dehidrodiisoeugenol en todos los casos, posiblemente por la formación de otros productos como trímeros, tetrámeros o polímeros.

\section{Conclusiones}

Podemos concluir que los cultivos celulares de $B$ ternifolia pueden ser empleados como catalizadores en la obtención de dehidrodiisoeugenol y las mejores condiciones de reacción, son las que utilizan el sobrenadante obtenido a partir de células en suspensión bajo condiciones de estrés nutritivo y sin adición de peróxido de hidrógeno (77\%). El rápido crecimiento de las células de $B$. ternifolia, su fácil disgregación y poca oxidación las hacen candidatos ideales para su uso como biocatalizador en la transformación de fenoles naturales.

\section{Agradecimientos}

Los autores agradecen al CONACYT Proyectos de Ciencia Básica 2012-CB180128 y 2009-CBIN129061, además el apoyo técnico de la QA. Mariana León-Pérez.

\section{Referencias}

Anita, Y., Widiyarti, G. \& Abbas, J. (2014). Synthesis and elucidation structure of O-para dehydroguaiacol prepared by crude of Brassica oleracea var. alboglabra peroxidasecatalyzed oxidation. Journal of Applied Pharmaceutical Science. 4, 062-065. DOI: 10.7324/JAPS.2014.40411

Bartolomeazzi, R., Verardo, G., Liessi, A. \& Callea, A. (2010). Formation of dehydrodiisoeugenol and dehydrodieugenol from the reaction of isoeugenol with DPPH radical and their Role in the radical scavenging activity. Food Chemistry. 118, 256-265. DOI: 10.1016/j.foodchem.2009.04.115

Farías-Días, A. (1988). An improved high yield synthesis of dehydrodieugenol Phytochemistry 27, 3008-3009. DOI: 10.1016/0031-9422(88)80715-5

Findik, E., Ceylan, M. \& Elmastaş, M. (2011). Isoeugenolbased novel potent antioxidants: synthesis and reactivity. European Journal of Medicinal Chemistry. 46, 4618-4624. DOI: 10.1016/j.ejmech.2011.07.041

Giri,A., Dhingra, V., Giri, C.C., Singh, A., Ward, O.P. \& Narasu, M.L. (2001). Biotransformations using plant cells, organ cultures and enzyme systems: current trends and future prospects. Biotechnology Advances. 19 (3)175-199. DOI: 10.1016/S0743-9750(01)85155-9

Hernández-Vázquez, L., Olivera-Flores, M.T.J., Ruiz-Terán, F., Ayala, I \& Navarro-Ocaña, A. (2011). Screening of plant cell culture for their capacity to dimerize eugenol and isoeugenol: preparation of dehydrodieugenol. Journal Molecular Catalysis. B: Enzymatic. 72, 102-106. DOI: 10.1016/molcab.2011.05.005

Hua, D., Ma, C., Lin, S., Song, L., Deng, Z., Maomy, Z., Zhang, Z., Yu, B. \& Xu, P. (2007). Biotransformation of Isoeugenol to vainillin by a newly isolated Bacillus pumilus strain: Identification of major metabolites. Journal of Biotechnology. 130, 463-470. DOI: 10.1016/j. biotec.2007.05.003

Ishihara, K.,Hamada, H., Hirata, T. \& Nakajima, N. (2003). Biotransformation using plant cultured cells. Journal Molecular Catalysis. B: Enzymatic. 23 (2.6), 145-170. 
DOI: $10.1016 / \mathrm{S} 1381-1177(03) 00080-8$

Juhász, L., Kürti, L. \& Antus, S. (2000). Simple synthesis of benzofuranoid neolignans from Myristica fragrans. Journal of Natural Products. 63, 866-870. DOI: 10.1021/ np990327h

Moussouni, S., Saru, M.L., Ioannou, E., Mansour, M., Detsi,A., Roussis, V. \& Kefalas, P. (2011). Crude peroxidase from onion solid waste as a tool for organic synthesis. Part II: oxidative dimerization-cyclization of methyl $p$-coumarate, methyl caffeate and methyl ferulate. Tetrahedron. Letters. 52, 1165-1168. DOI: 10.1016/j.tetlet.2011.01.004

Murakami, Y., Shoji, M., Hirata, A., Tanaka, S., Yokoe, I. \& Fujisawa, S. (2005). Dehydrodiisoeugenol, an Isoeugenol dimer, inhibits lipopolysaccharide-stimulated nuclear factor kappa B activation and cyclooxygenase-2 expression in macrophages. Archives of Biochemistry and Biophysics. 434, 326-332. DOI: 10.1016/j.abb.2004.11.013

Nascimento, I. R., Lopes, L. M. X., Davin, L. B. \& Lewis, N. G. (2000). Stereoselective synthesis of 8,9-1lcarinediols. Tetrahedron 56 (47), 9181-9193. DOI: 10.1016/S00404020(00)00873-5

Pereira, A.C., Magalhães L.G., Gonçalves, U.O., Luz, P.P., Moraes, A.C.G., Rodrigues, V., Da Matta Guades, P.M., Da Silva Filho, A.A., Cunha, W.R., Bastos, J.K., Nanayakkara, N.P.D., e Silva, M.L.A. (2011). Schistosomicidal and trypanocidal structure-activity relationships for $( \pm)$-licarin A and its (-)- and (+)-enantiomers. Phytochemistry 72, 14241430. DOI: $10.1016 /$ j.phytochem.2011.04.007
Ramachandra Rao, S \& Ravishankar, G.A. (1999) Biotransformation of isoeugenol to vanilla flavour metabolites and capsaicin in suspended and immobilized cell cultures of Capsicum frutescens: study of the influence of $\beta$-cyclodextrin and fungal elicitor. Process Biochemistry. 35(3-4), 341-348. DOI: 10.1016/s0032-9592(99)00077-1

Sánchez de Jiménez, E. \& Fernández, L. (1983). Biochemical parameters to assess cell differentiation of Bouvardia ternifolia Schlecht callus. Planta 158 (5), 377-383. DOI: 10.1007/BF00397728

Shiba, T., Xiao, L., Miyakoshi, T. \& Chen, C.-L. (2000). Oxidation of Isoeugenol and coniferyl alcohol catalyzed by laccases isolated from Rhus vernicifera Stokes and Pycnoporus coccineus. Journal of Molecular Catalysis. B: Enzymatic. 10 (6), 605-615. DOI: 10.1016/s13811177(00)00184-3

Suga, T. \& Hirata, T. (1990) Biotransformation of exogenous substrates by plant cell cultures. Phytochemistry 29, 23932406. DOI: 10.1016/0031-9422(90)85155-9

Wang, E.-C, Wein, Y-S. \& Kuo, Y-H. (2006). A concise and efficient synthesis of $\mathrm{s}$ alvinal from isoeugenol via a phenoxenium ion intermediate. Tetrahedron Letters. 47, 9195-9197. DOI: 10.1016/tetlet.2006.10.131

Wenqiang, G., Shufen, L., Ruixiang, Y., Shaoku, T. \& Can. Q. (2007). Comparison of essential oils of clove buds extracted with supercritical carbon dioxide and other tree traditional extraction methods. Food Chemistry. 101, 1558-1564. DOI: 10.1016/j.foodchem.2006.04.009 